\title{
Better representation is needed in Endangered Species Act implementation
}

\author{
Jacob Malcom ${ }^{1,2 *}$, Andrew Carter ${ }^{1,2}$ \\ ${ }^{1}$ Center for Conservation Innovation, Defenders of Wildlife, Washington DC 20036 \\ ${ }^{2}$ Environmental Science and Policy Department, George Mason University, Fairfax, VA 22030 \\ * Correspondence \\ Jacob Malcom \\ Center for Conservation Innovation \\ Defenders of Wildlife \\ jmalcom@defenders.org
}

Keywords: Endangered Species Act, representation, threatened species, endangered species, diversity, ecosystem

\begin{abstract}
The U.S. Fish and Wildlife Service uses the concepts of resilience, redundancy, and representationoften known as the "3Rs" - to guide implementation of the Endangered Species Act. The Service has done little, however, to relate the 3 Rs to the statutory requirements of the Act. Here we focus on interpreting the concept of representation given core tenets of science and conservation policy. We show that the Service's current interpretation, which focuses on a narrow set of characteristics intrinsic to species that facilitate future adaptation, falls far short of a reasonable interpretation from the scientific literature and other policy, and has significant consequences for the conservation of threatened and endangered species. To illustrate the shortcomings in practice, we discuss the case of the Lower 48 gray wolf (Canis lupus) delisting, the proposed Red-cockaded Woodpecker (Picoides borealis) downlisting, and the possible downlisting of the Canada lynx (Lynx canadensis). We then propose an alternative interpretation of representation that accommodates the Service's narrow interpretation and broadens it to include the importance of intraspecific variation for its own sake as well as extrinsic characteristics such as a species' role in ecological communities. We argue that this interpretation better reflects the intent of the Endangered Species Act, the best available science, and policy needs for conserving imperiled wildlife.
\end{abstract}

\section{Introduction}

The U.S. Endangered Species Act (Act) is often considered the strongest conservation law in the world for imperiled wildlife. Species that are likely to become in danger of extinction in the foreseeable future (threatened) or are presently in danger of extinction (endangered) receive significant protections under the law. However, determining whether a species qualifies as either threatened or endangered 
can be challenging (e.g., Doremus 1997). To improve the consistency of listing and delisting determinations, the U.S. Fish and Wildlife Service (Service) has chosen in recent years (Service 2016) to assess species status in terms of the "3Rs" of resilience, redundancy, and representation (Shaffer and Stein 2000).

The 3Rs are a useful framework for conservation, highlighting the need for populations to have geographic and demographic characteristics necessary to be resilient to transient shocks; to have sufficient redundancy to allow recovery from the (temporary) loss of populations to major events; and to have representation such that the diversity of biological systems is not lost. A detailed crosswalk between the 3Rs and the statutory requirements of the Act has not yet been done to our knowledge, but will ultimately be needed for the Service to fully connect its implementation to the requirements of the law. Before that can be complete, one significant shortcoming of the current implementation of the $3 \mathrm{R}$ framework by the Service must be addressed: how representation is evaluated.

Here, we first review how representation is interpreted in the scientific and policy literature. Next we show that Service practice in evaluating representation in recent years has deviated significantly from a reasonable interpretation of that meaning. This deviation has meant reducing or avoiding protections for species as Congress intended under the Act because key dimensions of representation have been ignored. We finally conclude with a proposal for a definition of representation that would place the Service on solid footing to meet its legal obligations under the ESA while employing the 3Rs as an organizing framework.

\section{Representation in the literature}

\section{Origin}

Shaffer and Stein (2000) articulated the 3Rs in a chapter in the book Precious Heritage: The Status of Biodiversity in the United States. They lay out a straightforward argument as to why these three characteristics of species, populations, communities, and ecosystems are necessary for conservation. In describing representation, they write:

Noah's ark is a common, but too simple, metaphor for biodiversity conservation. Biodiversity is composed of species, the genes they contain, the communities and ecosystems they form, and the processes that connect them. Consequently, successful biodiversity conservation means saving more than the species themselves. It means saving the ecological and evolutionary patterns and processes that not only maintain but also generate those entities we call species. Because every species' genetic makeup is shaped, through natural selection, by the environments it has experienced, successful conservation also means saving populations of each species in the array of different environments in which it occurs. ... The principle of representation-saving some of everything-will require identifying conservation targets not simply as species and communities but as the complexes of populations, communities, and environmental settings that are the true weave of biodiversity. (Emphasis added)

The authors use cougars (Puma concolor) as an example to illustrate the meaning of representation (Shaffer and Stein 2000 at 308). The species was formerly distributed across the entirety of both North and South America, but has been extirpated from many areas, including most of the eastern United 
States (83 FR 3086 (Feb. 22, 2018)). While we can technically "save" the species from total extinction if it is secure in just, say, Canada, that misses the point of conservation: we would be missing both diversity of cougars intrinsic to the species as well as missing their role in the environments in which they would otherwise inhabit (Shaffer and Stein 2000 at 308). The recovery of the Bald Eagle (Haliaatus leucocephalus) is a prime example of a species where this concept was met, with security across North America achieved.

Importantly, as we discuss further below, Congress recognized and endorsed the idea of representation when they passed the Act and required a threatened or endangered designation even when a species was not threatened with extinction across its entire range, but in a "significant portion of its range," and by allowing the listing of not just species but subspecies and distinct population segments (DPS), the latter being legally rather than biologically-defined entities meant to capture important but discrete components of larger species' populations as well. Indeed, a cougar subspecies or isolated subpopulation - the Florida panther - had already been designated as an endangered species in 1967 under the Act's precursor (32 FR 4001 (Mar. 11, 1967)). It remained listed under the new Act despite the fact that the widespread full species was not considered endangered or likely to become so in the foreseeable future. Intrinsic to the Act is this recognition that the diversity between populations within a species must be protected as a policy goal itself, rather than as a simple ward against global extinction. In the Act's "Findings, Purposes, and Policy" section, Congress explicitly stated that imperiled wildlife is of "esthetic, ecological, educational, historical, recreational, and scientific value to the Nation and its people." Each of those values are diminished by simply looking at representation in terms of species' global survival.

\section{Biological and ecological literature}

Essential concepts from biology and ecology are part of representation. Some dimensions of representation are fundamentally intrinsic characteristics, such as genetic and phenotypic diversity (e.g., Sommer et al. 2013, Forsman 2014). Indeed, entire domains of biology and ecology are dedicated to describing and understanding intrinsic diversity, such as the role of individual variation in ecological dynamics (e.g., Bolnick et al. 2011), evolution (e.g., Ellegren and Sheldon 2008) and, relatedly, systematics (Avise et al. 1987) and taxonomy (e.g., Blaxter 2004). There is a temporal component of intrinsic representation in conservation biology consisting both of the representation of diversity that arose in the past (Thomsen \& Willerslev 2015) and the potential for diversity into the future (Willis et al. 2007).

Fundamentally, we cannot fully describe a species only in terms of its intrinsic characteristics; we have to also include extrinsic characteristics, such as the species' impact on other communities and ecosystems. At its root, a species' role in a community is an essential part of its niche. The history of the niche concept goes back to at least the early 20th Century, was very relevant in 1973, and remains of central interest to community ecology today (see Chase and Leibold 2003 for a synthesis). One of the earliest papers to detail the idea of niches focused on the niche of California Thrasher (Toxostoma redivivum), a bird of desert scrub in southern California (Grinnell 1917). This paper is now generally understood as describing a species' needs for survival: the temperature and moisture regimes, the food items, the space for movement, etc., that is, the effect of the environment on a species. There is an equally important "Eltonian niche" concept, offered early in ecology and referencing the author of an 
early paper on the relationships among species (Elton 1927). Rather than envisioning the niche as the effects of the environment on a species, Elton described the niche as a species' effects on the environment, such as what a species eats (prey or forage), or how they affect energy and material flows through a system (e.g., beavers). Modern community ecology has synthesized these two complementary concepts of the niche to show that both are essential to understanding how species coexist and persist (see, e.g., Chase and Leibold 2003). Both the requirements and impacts components of the niche were well known by the time of the ESA's passage, and are reflected in the Act's prioritization of protecting species and habitat - "whereby the ecosystems upon which endangered species and threatened species depend may be conserved" ESA §2(b) — and its explicit recognition that imperiled species are, among other things, of "ecological . . value to the Nation and its people." ESA $\S 2(a)(3)$.

The description of representation from Shaffer and Stein (2000), which posits that representation includes a component extrinsic to a species because of effects individuals have on their environment, has a solid foundation in fundamental ecology. This interpretation is not new; for example, Carroll and colleagues (2010) concluded:

Those authors [Shaffer and Stein] defined representation as a species' presence across the diversity of ecosystems inhabited by the species and by the species' role in ecosystem processes. Representation applies primarily to a population itself (e.g., by examining whether the species' absence in a portion of its range would have significant ecological consequences or whether a given portion of a species' range includes ecosystem types not found elsewhere in the species' range)...

Further, it is essential to recognize that all of the intrinsic representation in the world does not matter for future diversification if there is nowhere for that diversification to play out by any evolutionary force. This idea is captured at least starting with Hutchinson's Ecological theater and the evolutionary play (1965) and carries through to today in the study of eco-evolutionary dynamics (e.g., Gillespie 2004, Fussmann et al. 2007, Hendry 2017, Aubree et al. 2020). This fundamental need is why Congress recognized the role of habitat protection as a critical part of the ESA: species must have a place for their conservation and evolution to play out.

\section{Legal context}

The Act is silent on how much representation is enough to consider a species conserved; after all, the seminal paper on the 3 Rs was written nearly 30 years after the law's initial passage and a decade after its last amendment. But two aspects of the law - the addition of the "significant portion of its range" [SPR] and "distinct population segments" [DPS] — in the legislative history of the Act provides critical insight into Congress's intent relative to representation. The Endangered Species Protection Act of 1969, which was the immediate predecessor of the Endangered Species Act, only referenced endangered species that were at risk of "worldwide extinction." (Pub. L. 91-135 §2 (1969)) (“[a] species . . . shall be deemed to be threatened with worldwide extinction whenever the Secretary determines . . . the continued existence of such species . . . [is] endangered"),Pub. L. 91-135 §2 (1969)). This meant that species could lose populations throughout large portions of their range and be secure in just a small portion, but never be considered endangered under American law. Congress recognized this shortcoming and updated the language in 1973 to include the phrase "throughout all or 
a significant portion of its range" in the definition of endangered species. (Threatened species inherit this requirement by virtue of their definition as "any species which is likely to become an endangered species within the foreseeable future throughout all or a significant portion of its range." (ESA §3(20)). Fundamentally, this definitional change between the 1969 and 1973 laws makes clear that Congress intended for the Act to go beyond mere existence of a species on the planet and to ensure species are represented across the significant portions of their range.

However, Congress did not specify what was meant by "significant" in this provision of the law, and the question remains open today. In 2001, the Ninth Circuit Court of Appeals found in Defenders of Wildlife v. Norton, 258 F.3d 1136 (9th Cir. 2001) that (among other things) the Service failed to follow the Act's required "significant portion of its range" analysis when it withdrew a proposed threatened listing for the flat-tailed horned lizard (Service 2011). The Service had reasoned that though the lizard faced habitat loss on private land, there was sufficient public land habitat to prevent the species from extinction. During the case the Service argued that threats to a species over a "significant portion of its range" would lead to listing only if threats in that portion of the range threatened the entire species' survival. The Court disagreed, finding such a requirement would mean this would effectively render the term "significant portion of its range" in the statute superfluous. Subsequent federal courts largely followed the reasoning set forth in that case, and as the issue become more frequently litigated, the Service began developing regulations to more precisely define just what "significant portion of its range" meant.

In 2007, an Interior Department solicitor (who would later head the department when it developed new regulations interpreting "significant portion of its range" in 2019, see below) issued a legal memorandum ("M-Opinion") on the SPR issue, arguing that the Act in fact gave the Service the authority to designate a species as endangered only in that portion of the range where it was threatened with extinction (Service 2007). This unusual argument, which flew in the face of decades of ESA implementation, was later rejected by the courts and withdrawn by the Department of Interior (76 FR 76987 (Dec. 9, 2011)).

Finally, in 2014 the Service and the National Marine Fisheries Service published a rule codifying how "significant" in "significant portion of its range" should be interpreted (79 FR 37609 (July 1, 2014)):

Significant: A portion of the range of a species is "significant" if the species is not currently endangered or threatened throughout its range, but the portion's contribution to the viability of the species is so important that, without the members in that portion, the species would be in danger of extinction, or likely to become so in the foreseeable future, throughout all of its range.

The new definition is still inconsistent with both the tenets of conservation biology as well as the purposes of the Endangered Species Act. First, it once again evaluates significance by looking at the portion of the range solely in terms of how it contributes to the entire species' survival, ignoring conservation goals and the plain language of the Act. Second and most relevant to the present contribution, it ignores fundamental aspects of ecological science and the core ideas of representation, including the role of species in the ecosystem. Under the 2014 interpretation, this is akin to, "Relegating grizzlies to Alaska is about like relegating happiness to heaven; one may never get there," as the court in Defenders of Wildlife v. Norton stated when quoting Aldo Leopold (Defenders of 
Wildlife v. Norton, 258 F.3d 1136, 1145 (9th Cir. 2001)). This definition is no longer in effect, as the Services' interpretation of "significant portion" of its range has been vacated nationwide by a federal court that (like the 9th Circuit in Defenders of Wildlife v. Norton) took issue with the fact that the Service's definition once again rendered the "significant portion" language in the statute superfluous (Desert Survivors v. U.S. Dep't of the Interior, 336 F. Supp. 3d (N.D. Cal. 2018).

The second major aspect of legislative history evidencing Congress' intent to protect representation in a broad fashion in the Act is the expansion between 1969 and 1973 of what entities could be protected. While the 1969 Act allowed the government to protect a "species or subspecies of fish or wildlife" (which it left undefined), the 1973 Act expanded the definition of species to include not just species or subspecies but also "any other group of fish or wildlife of the same species or smaller taxa in common spatial arrangement that interbreed when mature.” (Pub. L. 93-205 (1973)). A subsequent 1978 amendment changed that, limiting the group to vertebrates but also removing the common spatial arrangement requirement, defining species as including "any distinct population segment of any species of vertebrate fish or wildlife which interbreeds when mature" (Pub. L. 95-632 (1978)), known generally as Distinct Population Segments (DPS). Current DPS policy creates a two-prong test for determining whether a population qualifies as a DPS: the discreteness and the significance of the population (61 FR 4722, Feb. 7, 1996). Representation is central to the question of significance, but the relationship between the two ideas has not been articulated to date. As described in preceding sections, it is natural - and necessary - that questions of significance consider both intrinsic and extrinsic components of representation. At some level, the Service recognizes this; for example, a 2014 Service presentation on DPS interpretation highlighted that it should advance the goals of " 1 . Conserving genetic resources; and, 2. Maintaining natural systems and biodiversity over a representative portion of their historic occurrence" (SI Appendix 1, Service 2014) ${ }^{1}$.

\section{Synthesis}

In sum, the biological and ecological literature promote a concept of representation that is expansive. It is about representing characteristics intrinsic to a species like phenotypic and genetic diversity, including diversity that arose in the past and enabling diversity that may arise in the future. Representation is also about extrinsic characteristics, like the impacts the species has on the community or ecosystem as part of communities and ecosystems. Such an understanding is fully consistent with the Endangered Species Act, which explicitly requires conservation not just of imperiled species as a whole, but of important portions of their habitat, genetically and geographically distinct components of their larger populations, and the ecosystems on which they depend and are an integral part.

\footnotetext{
${ }^{1}$ It should be noted that Congress also did not define "range," which has also been a source of tension in interpreting the Act for decades (Enzler \& Bruskotter, 2009). Some authors have argued that the intention was historic range (Enzler \& Bruskotter 2009, Vucetich et al. 2006), and some of the Service's early statements and decisions appeared to follow this interpretation (Enzler \& Bruskotter 2009). However, more recent Service rationales (Enzler \& Bruskotter 2009, 79 Fed. Reg. 37,578 (July 1, 2014)) have argued that Congress only meant range at the time of listing, unless such range is insufficient for the conservation of the species. A recent court decision by the 9th Circuit held that "range" in the statute is ambiguous and indicated that the court will defer to the Service's interpretation as to whether it should be read as historic or current (Ctr. for Biological Diversity v. Zinke, 900 F.3d 1053, 1066-1067 (9th Cir. 2018)).
} 


\section{Representation from the Service}

In contrast to the broad concept from Shaffer and Stein (2000), the well-established concepts in ecology, and reasonable interpretations of Congress's intent for the Act, the Service has a very narrow interpretation of representation, even while they cite Shaffer and Stein (Service 2016):

Representation describes the ability of a species to adapt to changing environmental conditions over time. It is characterized by the breadth of genetic and environmental diversity within and among populations. Measures may include the number of varied niches occupied, the gene diversity, heterozygosity or alleles per locus. Our analysis explores the relationship between the species life history and the influence of genetic and ecological diversity and the species ability to adapt to changing environmental conditions over time. The analysis identifies areas representing important geographic, genetic, or life history variation (i.e., the species' ecological settings).

There are several ways in which this falls short. First, in the first sentence, the Service's interpretation of representation diverges from the concept as articulated by Shaffer and Stein (2000) and the scientific and policy literature as outlined above, such that citing those authors to support the interpretation is misleading. This is later reinforced in describing how their analysis explores "...the species ability to adapt to changing environmental conditions over time." There is nothing in the Service's interpretation that captures the idea of protecting existing biological variation for its own sake; it only references protecting variation as a guard against future conditions to which the species may need to adapt. It is difficult to square this narrow focus on species variation with Congress's direction to protect the diversity of species across their range and its declaration in the Act that biodiversity is of value to the nation.

Second, while niches and "ecological settings" are mentioned in subsequent sentences of the Service's interpretation, they appear to be more of an afterthought; there is no explicit recognition that species should be secure in those different ecological settings, fulfilling their ecological roles in their communities. But those ideas are essential to meeting the ideas of representation from Shaffer and Stein and elsewhere in the literature, and the concept of SPR embodied in the Act. A reasonable interpretation of representation would recognize this aspect.

Third, it is not enough to just identify some characteristics of representation; there should be examples of how much representation is enough to meet the Act's mandates. For example, how much allelic diversity does the Service believe needs to be maintained to ensure the species' diversity is represented? Or, is securing the species' existence in one of two ecosystems where it is found sufficient to represent the species in significant portions of the range as Congress intended? Without sideboards on these types of questions, the Service cannot offer a clear explanation of why any given species' representation is sufficient to meet the Act's mandate.

Not only are these aspects of the Service's interpretation inconsistent with the scientific and policy literature on representation, but they are also inconsistent with the statutory goals of the Endangered Species Act itself. And while insufficient on its face, the narrow interpretation has harmful consequences in implementation, which we illustrate with an example of Lower 48 gray wolves. 


\section{Examples: Lower 48 wolves, Red-cockaded woodpecker, and Canada lynx}

The flaws in the Service's current approach to interpreting "representation" and the consequences for applying Congressional intent with the inclusion of "significant portion of its range" in the 1973 Act can be seen throughout its listing and other decisions in recent years. Below we consider representation in more detail for Service decisions concerning the Lower 48 gray wolf (Canis lupus), the redcockaded woodpecker (Picoides borealis), and the Canada lynx (Lynx canadensis).

\section{Lower 48 Gray Wolf (Canis lupus)}

Various subspecies and/or distinct population segments of the gray wolf have been listed since 1967. In 2019, the Service proposed to delist the Lower 48 population of gray wolves, that is, every gray wolf other than the Mexican gray wolf (Canis lupus baileyi) found in the lower 48 states (USFWS 2019) and finalized the delisting in 2020. Their argument is that the species is no longer at risk of extinction, nor is it likely to become at risk of extinction, throughout all or any significant portion of its range. To arrive at this conclusion, the Service takes an unreasonably narrow interpretation of representation in this proposed rule, first invoking the 3Rs and Shaffer and Stein, then reducing the listed entity to the bounds of the Great Lakes wolves (USFWS 2019, emphasis added):

The metapopulation in the Great Lakes area contains sufficient resiliency, redundancy, and representation to sustain populations within the gray wolf entity over time. Therefore, we conclude that the relatively few wolves that occur outside the Great Lakes area within the gray wolf entity, including those in the west coast States and lone dispersers in other States, are not necessary for the recovered status of the gray wolf entity.

The Service justified this conclusion by recounting:

After reviewing the biology of the gray wolf entity and potential threats, we have not identified any portions of the gray wolf entity for which both (1) gray wolves may be in danger of extinction or likely to become so in the foreseeable future and (2) the portion may be significant. While some portions may be at increased threat from human-caused mortality or factors related to small numbers, we did not find that any of these portions may be significant. We provide examples below.

Among the examples, the glaring error in the interpretation of representation is given in the third example, which focuses on the West Coast wolves and which is key to the decision to delist:

Third, the west coast portion of the gray wolf entity, where wolves exist in small numbers in California, western Oregon, and western Washington, also is not biologically important to the gray wolf entity in terms of resiliency, redundancy, or representation. ... This portion is also not important in terms of representation, because (1) gray wolves are a highly adaptable generalist carnivore capable of long-distance dispersal, and (2) the gray wolves in this area are an extension of a large metapopulation of wolves in the northern Rocky Mountains and western Canada (i.e., they are not an isolated population with unique or markedly different genetic or phenotypic traits that is evolving separate from other wolf populations). Therefore, for the purpose of assessing the status of the gray wolf entity under the Act, we do not find that this portion may be significant under any reasonable definition of "significant" because it is 
not biologically important to the gray wolf entity in terms of its resiliency, redundancy, or representation.

As discussed at length above, a proper interpretation of representation for any species should capture the many dimensions of diversity, intrinsic and extrinsic. Here, the Service's position that the wolf populations of the Pacific states are not significant is unreasonable for several reasons. Intrinsically, science has established that some of these populations contain alleles of coastal wolves from British Columbia not represented in the interior Northern Rocky Mountains populations (Hendricks et al. 2019). Just as important, the Service's position is in error because it excludes the major extrinsic factor for which wolves are well-known: their role in shaping ecosystems (Ripple and Beschta 2012; but see Peterson et al. 2014). Regardless the details of wolves in driving trophic cascades, their role as top predators cannot be ignored or written off as insignificant. These Lower 48 wolf populations occupy different ecosystems (U.S. Environmental Protection Agency 2015) and therefore represent unique roles given the variation in ecological interactions among the ecosystems. It is unreasonable-even incoherent - to claim that the "best available scientific and commercial data" (16 U.S.C.

$\S 1533(\mathrm{~b})(1)(\mathrm{A}))$ are being used in a decision while ignoring this critical aspect of representation, deeply rooted in the scientific literature. Therefore, the clear ecological significance that the Pacific states wolves represent, combined with the wolves' tenuous existence-small populations, the threat of hunting, trapping, and poaching, and exposure to other threats such as vehicle traffic, as the Service recounts in the rule - means that the Lower 48 wolf must remain listed until they are as secure as populations such as the Great Lakes wolves.

\section{Red-cockaded Woodpecker (Picoides borealis)}

Similar flaws can be seen in the Service's proposal to downlist the red-cockaded woodpecker from endangered to threatened. The red-cockaded woodpecker has been listed as endangered since 1970, but recently was proposed to be downlisted to threatened (USFWSa 2020), despite the fact that the species is at risk of extinction throughout much of its range. As with the Lower 48 gray wolf delisting, the Service takes an unreasonably narrow interpretation of representation in the proposed red-cockaded woodpecker downlisting, again invoking the 3 Rs and Shaffer and Stein but then finding that despite the fact that significant threats to the species across three ecoregions, containing $40 \%$ of the species' populations (emphasis added):

Even if some populations in these portions were to become extirpated, the species would maintain sufficient levels of resiliency, representation, and redundancy in the rest of these ecoregions and in other ecoregions across its range, supporting the species' viability as a whole. Thus, we do not find that these are portions of the red-cockaded woodpecker's range that may be significant. (USFWS 2020a:63,492)

The Service's focus on "the species' viability as a whole" again narrows representation to only look at whether representation is sufficient to ensure the entire species' likely survival into the future, excluding consideration of significant portions of its range as Congress requires. In its Species Status Assessment and its proposed downlisting rule, the Service admits that: (1) the species has already been extirpated from seven of the ecoregions in which it was historically found (USFWS 2020b:116); (2) is further under threat of extinction due to a combination of hurricanes and small population sizes in an additional two others (and part of a third) (USFWS 2020:63,493); (3) has only a small number of low 
or very-low resilience populations in six of the remaining ecoregions (USFWS 2020b:117); and (4) "[a]11 of the populations in [these] six ecoregions are of low or very low resilience, but are important for representation in their respective regions and across the range" (USFWS 2020:9). Yet by relying on the unduly narrow definition of representation, the Service still holds that "we do not find any portions of the species' range may be significant based on their biological importance to the overall viability of the red-cockaded woodpecker" (USFWS 2020a:63,492). The species' fairly healthy populations in a small number of the ecoregions, representing a fraction of even its current range, appears to mean to the Service that the requirement of representation is met.

The Service's position that the red-cockaded woodpecker populations across six ecoregions do not constitute a "significant portion of its range" is unreasonable for several reasons. These red-cockaded woodpeckers occupy different pine ecosystems and therefore represent unique roles given the variation in ecological interactions among the ecosystems. Indeed, by definition, these different ecoregions represent different ecological settings - and maintaining adequate representation should take into account the species' viability in and relationship to those ecological settings when determining what constitutes representation. The importance of this ecological variation is apparent because the Service developed recovery units for the species. Recovery units are defined by the Services as geographic areas "individually necessary to conserve genetic robustness, demographic robustness, important life history stages, or some other feature necessary for long-term sustainability of the entire listed entity" (emphases in original) (NMFS 2010; Evans et al. 2020). Here, the Service chose to delineate redcockaded woodpecker recovery units by ecoregion. In its recovery plan, the Service further noted that "[c]onservation of populations in all habitat, forest types, and ecoregions, represented within and by recovery units is critical to species survival because these varied populations have crucial ecological and genetic values" (emphasis added) (USFWS 2003). This fundamentally recognizes the importance of the species' role in different ecosystems and one of the core concepts of representation, only to be ignored by the Service in its proposal to downlist.

\section{Lower 48 Canada Lynx (Lynx canadensis)}

The Canada lynx was listed as threatened under the ESA in 2000; as with the gray wolf, only the Canada lynx population segment found in the contiguous United States is listed. Although its 2018 statutorily required five-year review carried out by the Service recommended delisting the species due to recovery (USFWS 2017), at the time of this writing a proposed delisting rule has not been published, though it is pending on the Department of the Interior's online agenda.

In the species' five-year review, the Service offers an even narrower view of representation than it has done with the lower 48 gray wolf or Red-cockaded Woodpecker, reducing it solely to the species' adaptive capacity as reflected by its genetic diversity. The Service reasons (emphasis added):

Additionally, observed high rates of dispersal and gene flow and therefore generally low levels of genetic differentiation across most of the lynx's range, including the DPS, suggest the past and recent genetic health of lynx populations in the DPS (representation) (SSA Report, section 2.1). Because there are no indications of significant loss of, or current stressors to, the genetic health or adaptive capacity of lynx populations in the DPS, we find that the current level of representation within the DPS does not appear to indicate a decrease from historical conditions ....(USFWS 2017) 
Focusing solely only on a subset of intrinsic genetic characteristics in its representation analysis, the Service ignores other aspects of representation that should be incorporated, such as the role of the Canada lynx as a key predator in the variety of ecosystems it inhabits. For example, Species Status Assessment notes that:

Despite similarities in the fundamental components (vegetation, snow conditions, and hares) that define the ecological niche of lynx DPS-wide, differences in habitats and how lynx use them are apparent. . . The loss of resident lynx from any of the geographic units could result in the loss of behavioral and potential future genetic adaptations to the climate-mediated changes now occurring and likely to continue into the future at the southern edge of the lynx range. Such potential adaptability to diminished snow conditions, increasingly patchy and isolated boreal forests, and reduced hare abundance may be important to the taxon as a whole faced with a rapidly changing climate. (USFWS 2017 p. 235).

As with the gray wolf and the red-cockaded woodpecker, the Service's representation analysis does not acknowledge the importance of maintaining the Canada lynx across these differences in habitats and how different lynx populations shape their communities.

Last, we note that while we have illustrated the shortcomings of the Service's current interpretation of representation through the lens of the Lower 48 gray wolf delisting proposal, the red-cockaded woodpecker downlisting proposal, and the Canada lynx delisting recommendation, there are many other examples, such as the northern long-eared bat (Myotis septentrionalis) and dozens if not hundreds of other species for which proper interpretation of representation is critical. The fundamental meaning of representation and these concrete cases highlight the need for a better interpretation by the Service.

\section{Actionable Recommendation: Better representation}

To ensure that the intent of Congress is fulfilled as it carries out the Act, the Service needs to revise its interpretation of representation. Below we offer a proposed interpretation that more accurately reflects the original intent from Shaffer and Stein (2000), the science of representation, and the clear intent of Congress in its directive to conserve imperiled biodiversity:

Representation means the characteristics that make a species a contributor to biodiversity, whether intrinsic or extrinsic to individuals and populations. This includes representation of standing diversity in genetics and phenotypes to represent current diversity and to ensure sufficient genetic and phenotypic variation to allow for future diversification. It also means representation in the variety of ecosystems in which the species is found, and with the variety of interactions with other species, such that the species' role in those ecosystems is maintained.

This interpretation is a superset of that of the Service, incorporating the narrow issue of representative variation for the purpose of future adaptation while also acknowledging the intent of protecting standing diversity for its own sake. It adopts the critical recognition of a species' role in ecological communities and ecosystems as an essential dimension of representation. It also places bounds on how much representation is enough, e.g., "standing diversity... and sufficient...variation to allow future 
diversification" and "the variety of ecosystems in which the species is found". Therefore, not only is this definition more consistent with the intent of Shaffer and Stein (2000), it is consistent with the scientific literature that reflects our understanding of ecology and it is surely more consistent with Congressional intent for protecting wildlife and their habitats.

This improved interpretation is not superficial; it has broad, real-world implications. Most importantly, a reasonable interpretation of "significant" for listing, recovery planning, and delisting decisions under section 4 of the Act must include significant characteristics intrinsic and extrinsic to a species given the proposed interpretation of representation. For example, rather than viewing standing genetic and phenotypic diversity as something important only for future adaptive capacity, it would need to be conserved for its own sake. Critically, there is nothing to suggest the "purpose" of the variation must be functionally understood to be protected - we are just now starting to build such understanding in most ecological contexts (Becks et al. 2012, Des Roches et al. 2018)—simply that it exists. With respect to extrinsic aspects of a species' representation and section 4 decisions, one simple and effective operational standard could be for the Service to adopt the EPA's (Environmental Protection Agency 2020) or similar ecosystem classification system for analysis. If the Service found any part of a species' range in different ecosystems, each would be considered significant and therefore require conservation under the Act. Such spatial overlap is not the only measure of extrinsic significance of course; it could also be other important interactions with the species' ecological community. With an explicit significance determination, aspects from recovery planning and criteria (Carroll et al. 2010) to recovery units (Evans et al. 2020) to the five-factor threat analysis for listing and delisting decisions are affected in ways that further protect species using existing tools in section 4 of the Act.

In addition to application to section 4, this interpretation may have implications for implementing other parts of the Act. For example, it could require that the scope of jeopardy and adverse modification analysis under section 7(a)(2) consultation focus on significant portions of an impacted species, not just their full range. This would be akin to one application of "recovery units," which are portions of a species' range identified in recovery plans as essential to the recovery of a species and therefore subject to being conserved to avoid jeopardy (NMFS \& Service 2010, Evans et al. 2020). This interpretation would have the potential to significantly reduce the risk of "death by a thousand cuts" that remains challenging in imperiled species conservation (Malcom and Li 2015, Evans et al. 2019, Evansen et al. 2020). Further analysis of this possibility is beyond the scope of the current paper, but highlights that additional consequences are likely and remain to be discovered and understood if representation is given its due.

\section{Conclusion}

Congress found nearly 50 years ago that protecting biodiversity was in the national interest, and with the Endangered Species Act, passed what is now widely considered the strongest imperiled wildlife protection law in the world. Key updates to the Act emphasize the idea of protecting against the loss of species from all significant portions of their range as well as distinct population segments, not just protecting species from global extinction. While the Service has worked to bring additional science to bear on their decision-making with the integration of the 3Rs, such as in the identification of significant portions of a species' range, the agency's interpretation of representation has been particularly lacking. If the Service adopts a better, more science-based interpretation of 
representation - such as the one proposed here-the consequences for the conservation of threatened and endangered species will be substantial and widespread. Absent such a change, the Service will continue to fall short of Congress's clear intent of the value of conserving wildlife throughout all significant portions of their range.

\section{Author Contributions}

Both JWM and AC wrote the manuscript and approved the submitted version.

\section{Funding}

Funding for this work was provided by members and supporters of the authors' employer, Defenders of Wildlife.

\section{Conflict of Interest}

The authors declare that the research was conducted in the absence of any commercial or financial relationships that could be construed as a potential conflict of interest.

\section{Acknowledgements}

We thank J. Rylander, R. Dreher, and members of the Center for Conservation Innovation for discussions of the issues covered in this paper, especially on Significant Portion of its Range and relevant case law, which helped us improve the science-policy integration in this contribution. [And we thank \# reviewers for constructive critical reviews.]

\section{References}

Aubree F, David P, Jarne P, Loreau M, Mouquet N, Calcagno V. 2020. How community adaptation affects biodiversity-ecosystem functioning relationships. Ecology Letters 23: 1263-1275.

Avise JC. 1987. Intraspecific phylogeography: the mitochondrial DNA bridge between population genetics and systematics. Annual Review of ecology and Systematics 18: 489-522.

Becks L, Ellner SP, Jones LE, Hairston NG. 2012. The functional genomics of an eco-evolutionary feedback loop: Linking gene expression, trait evolution, and community dynamics. Ecology Letters 15 : 492-501.

Blaxter ML. 2004. The promise of a DNA taxonomy. Philosophical Transactions of the Royal Society B: Biological Sciences 359: 669-679.

Bolnick DI, Amarasekare P, Araújo MS, Bürger R, Levine JM, Novak M, Rudolf VHW, Schreiber SJ, Urban MC, Vasseur DA. 2011. Why intraspecific trait variation matters in community ecology. Trends in Ecology and Evolution 26: 183-192. 
Carroll C, Vucetich JA, Nelson MP, Daniel J, Phillips MK, Phillips MK. 2010. Geography and

Recovery under the U.S. Endangered Species Act. Conservation Biology 24: 395-403.

Chase JM, Leibold MA. 2003. Introduction: History, Context, and Purpose. Pages 1-18 in. Ecological Niches : Linking Classical and Contemporary Approaches.

Des Roches S, Post DM, Turley NE, Bailey JK, Hendry AP, Kinnison MT, Schweitzer JA, Palkovacs EP. 2018. The ecological importance of intraspecific variation. Nature Ecology and Evolution 2: 5764.

Doremus H. 1997. Listing Decisions Under the Endangered Species Act: Why Better Science Isn’t Always Better Policy. Washington University Law Review 75.

Ellegren H, Sheldon BC. 2008. Genetic basis of fitness differences in natural populations. Nature 452: 169-175.

Elton CS. 1927. Animal Ecology. University of Chicago Press, Chicago. 296pp.

Enzler SA, Bruskotter JT. 2009. Contested Definitions of Endangered Species: The Controversy Regarding How to Interpret the Phrase A Significant Portion of a Species Range. Virginia Environmental Law Journal 27: 1-66.

Evans M, Li Y-W, Malcom J. 2020. Recovery Units under the Endangered Species Act could be used more widely. bioRxiv 2020.03.15.991174.

Evansen M, Li Y-W, Malcom J. 2020. Same law, diverging practice: Comparative analysis of Endangered Species Act consultations by two federal agencies. PLOS ONE 15: e0230477.

Forsman A. 2014. Effects of genotypic and phenotypic variation on establishment are important for conservation, invasion, and infection biology. PNAS 111: 302-307.

Fussmann GF, Loreau M, Abrams PA. 2007. Eco-Evolutionary Dynamics of Communities and Ecosystems. Functional Ecology 21: 465-477.

Gillespie R. 2004. Community Assembly through Adaptive Radiation in Hawaiian Spiders. Science 303: $356-359$.

Grinnell J. 1917. The Niche-Relationships of the California Thrasher. The Auk 34: 427-433.

Hendry AP. 2016. Eco-evolutionary Dynamics. Princeton University Press, Princeton. 416pp.

Hendricks, S.A., Schweizer, R.M., Harrigan, R.J., Pollinger, J.P., Paquet, P.C., Darimont, C.T., Adams, J.R., Waits, L.P., vonHoldt, B.M., Hohenlohe, P.A. \& Wayne, R.K. (2019). Natural recolonization and admixture of wolves (Canis lupus) in the US Pacific Northwest: challenges for the protection and management of rare and endangered taxa. Heredity, 122, 133-149.

Hutchinson GE. 1965. The Ecological Theater and the Evolutionary Play. First Edition. Yale University Press, New Haven. 
Vucetich JA, Nelson MP. 2014, August 20. Conservation, or Curation? The New York Times.

Available from https://www.nytimes.com/2014/08/21/opinion/conservation-or-curation.html (accessed December 31, 2020).

NMFS, U.S. Fish and Wildlife Service. 2010. Interim Endangered and Threatened Species Recovery Planning Guidance.

Peterson, R.O., Vucetich, J.A., Bump, J.M. \& Smith, D.W. 2014. Trophic Cascades in a Multicausal World: Isle Royale and Yellowstone. Annu. Rev. Ecol. Evol. Syst., 45, 325-345.

Ripple, W.J., Beschta, R.L. 2012. Trophic cascades in Yellowstone: The first 15years after wolf reintroduction. Biological Conservation, 145, 205-213.

Shaffer ML, Stein BA. 2000. Safeguarding our Precious Heritage. Precious Heritage: The Status of Biodiversity in the United States.

Thomsen PF, Willerslev E. 2015. Environmental DNA - An emerging tool in conservation for monitoring past and present biodiversity. Biological Conservation 183: 4-18.

U.S. Environmental Prot. Agency. Level III and IV Ecoregions of the Continental United States. https://www.epa.gov/eco-research/level-iii-and-iv-ecoregions-continental-united-states. Accessed 9 September 2020 .

U.S. Fish and Wildlife Service (USFWS). 2003. Recovery plan for the Red-cockaded Woodpecker: Second revision. 316pp. Atlanta, GA. Available from https://ecos.fws.gov/docs/recovery_plan/030320_2.pdf (accessed December 31, 2020).

U.S. Fish and Wildlife Service. 2016. USFWS species status assessment framework. https://www.fws.gov/endangered/improving_esa/pdf/SSA\%20Framework\%20v3.4-8_10_2016.pdf. Accesses 9 September 2020.

U.S. Fish and Wildlife Service. 2017. Canada lynx (Lynx canadensis) Five-year Review: Summary and Evaluation. 10pp. Lakewood, Colorado. Available from https://ecos.fws.gov/docs/five year_review/doc5667.pdf

U.S. Fish and Wildlife Service. 2019. Endangered and Threatened Wildlife and Plants; Removing the Gray Wolf (Canis lupus) From the List of Endangered and Threatened Wildlife, Proposed Rule. Federal Register 84:9648-9687.

U.S. Fish and Wildlife Service. 2020a. Endangered and Threatened Wildlife and Plants; Reclassification of the Red-Cockaded Woodpecker From Endangered to Threatened With a Section 4(d) Rule, Proposed Rule. Federal Register 85:63474-63499.

U.S. Fish and Wildlife Service. 2020b. Species Status Assessment Report For the Red-cockaded Woodpecker (Picoides borealis) Version 1.3. 590pp. Atlanta, GA. Available from https://ecos.fws.gov/ServCat/DownloadFile/188805 
Vucetich JA, Nelson MP, Phillips MK. 2006. The normative dimension and legal meaning of endangered and recovery in the U.S. Endangered Species Act. Conservation Biology 20: 1383-1390.

Willis KJ, Araújo MB, Bennett KD, Figueroa-Rangel B, Froyd CA, Myers N. 2007. How can a knowledge of the past help to conserve the future? Biodiversity conservation and the relevance of long-term ecological studies. Philosophical Transactions of the Royal Society B: Biological Sciences 362: 175-186. 